\title{
Upper airway and systemic inflammation in obstructive sleep apnoea
}

\author{
Eugenio Vicente $e^{1,2,3,9}$, Jose M. Marin 2,3,4,9 , Santiago J. Carrizo $2,3,4$, \\ Carlos S. Osuna ${ }^{5}$, Ricardo González ${ }^{6}$, Marta Marin-Oto ${ }^{7}$, Marta Forner $^{2,3,7}$, \\ Paul Vicente ${ }^{7}$, Pablo Cubero ${ }^{3,7}$, Ana V. Gil ${ }^{3,7}$ and Xavier Soler ${ }^{8}$
}

Affiliations: ${ }^{1}$ Otorhinolaryngology Dept, Hospital Miguel Servet, Zaragoza, Spain. ${ }^{2}$ CIBER Enfermedades Respiratorias, Madrid, Spain. ${ }^{3}$ Instituto de Investigación Sanitaria de Aragón, Zaragoza, Spain. ${ }^{4}$ Respiratory Dept, Hospital Miguel Servet, Zaragoza, Spain. ${ }^{5}$ Haematology Dept, Hospital Miguel Servet, Zaragoza, Spain. ${ }^{6}$ Biochemistry Dept, Hospital Miguel Servet, Zaragoza, Spain. ${ }^{7}$ Translational Research Unit, Instituto de Investigación Sanitaria de Aragón, Zaragoza, Spain. ${ }^{8}$ Pulmonary, Critical Care and Sleep Division, UCSD, San Diego, USA. ${ }^{9}$ Both authors contributed equally.

Correspondence: Jose M. Marin, Respiratory Dept, Hospital Universitario Miguel Servet, 1-3, Isabel la Catolica, 50006-Zaragoza, Spain. E-mail: jmmarintdunizar.es

ABSTRACT Obstructive sleep apnoea (OSA) is associated with pharyngeal inflammation, but the coexistence of systemic inflammation is controversial. This study investigated whether local and systemic inflammatory biomarkers are related in patients with OSA. An uncontrolled extension to the study assessed the response to effective treatment.

We recruited 89 patients with OSA (apnoea/hypopnoea index (AHI) $\geqslant 5$ events.h ${ }^{-1}$ ), 28 snorers and 26 healthy controls. Pharyngeal lavage (PHAL) and plasma samples were collected at baseline and after a 1-year follow-up. Inflammatory cells were evaluated by flow cytometry; interleukin (IL)-6, IL-8 and tumour necrosis factor- $\alpha$ were evaluated by immunoassay.

In PHAL, CD4 ${ }^{+}$T-cells, IL-6 and IL- 8 were higher in OSA patients than in snorers or healthy controls $(\mathrm{p}<0.05)$. The AHI correlated with $\mathrm{CD}^{+}$, IL-6 and IL-8 in PHAL (all p-values $<0.05$ ). There were no differences in the inflammatory biomarkers in plasma between the study groups and no relationship between plasma and PHAL biomarkers. Biomarkers decreased significantly in PHAL but not in plasma after 1 year of therapy with continuous positive airway pressure or surgery.

In patients with OSA, increased levels of inflammatory biomarkers were found in PHAL, which were reduced with effective treatment. No simultaneous increase in plasma inflammatory biomarkers was found.

@ERSpublications

Pharyngeal lavage, but not plasma, shows high levels of inflammatory markers in OSA that were normalised by treatment http://ow.ly/pKYd301hs6A

Editorial comment in Eur Respir J 2016; 48: 982-983.

This article has supplementary material available from erj.ersjournals.com

Received: Jan 312016 | Accepted after revision: June 112016 | First published online: Sept 012016

Support statement: This study was funded by Instituto de Salud Carlos III (PI10/02696), Ministry of Health, Madrid, Spain and by an unrestricted grant from Esteve Teijin laboratory. The sponsor had no role in the design of the study, the collection and analysis of the data, or in the preparation of the article. Funding information for this article has been deposited with the Open Funder Registry.

Conflict of interest: None declared.

Copyright OERS 2016 


\section{Introduction}

Obstructive sleep apnoea (OSA) is defined by total or partial collapse of the upper airway resulting in nocturnal hypoxaemia and arousal from sleep. Repetitive airway closure and reopening do not only lead to local mechanical stress, but also result in inflammation of the mucosa [1-5]. In patients with OSA, biopsies of the upper airway tissue have demonstrated subepithelial oedema and excessive inflammatory cell infiltration [1-5]. In addition, their exhaled breath contained elevated levels of nitric oxide and other biomarkers of inflammation. Furthermore, increased expression of systemic inflammatory biomarkers has been reported in patients with OSA [6-10]. Since ongoing inflammatory responses play crucial roles in atherosclerosis [11, 12], these abnormalities are probably implicated in the increased cardiovascular and cerebrovascular morbidity found in these patients [13]. Increased levels of proinflammatory cytokines involved in the atherosclerotic process, such as interleukin (IL)-6 and C-reactive protein (CRP), have been reported in OSA $[14,15]$. These cytokines are also increased in other conditions such as obesity [16], which can be a confounding factor in patients with OSA. On the other hand, some studies have not shown an independent association between OSA and IL-6 and/or CRP levels $[17,18]$. Thus, there is controversy about the relationship between these cytokines and OSA.

Intermittent hypoxia increases the sympathetic response and, if combined with oxidative stress, is thought to play an essential role in the development of chronic systemic inflammation in OSA [19-21]. Notwithstanding, nocturnal oxygen therapy used to resolve intermittent hypoxaemia present in OSA did not result in any changes in inflammatory cytokines [22]. As a matter of fact, the response to OSA treatment with continuous positive airway pressure (CPAP) has been variable $[15,22]$. An alternative mechanism could lead to a systemic inflammatory response releasing inflammatory proteins and immune mediators from the upper airway mucosa that spill over into the circulation. Given that no data are available regarding the association between upper airway and systemic inflammation in OSA and that such information may be relevant to the design of treatment strategies in these patients, this study was conducted to evaluate the association between local and systemic inflammation in three groups: 1) subjects with OSA; 2) snorers; and 3) healthy controls. Subsequently, the effect of OSA treatment on this association in these groups was assessed.

\section{Methods}

A detailed explanation of the methods used is provided in the supplementary material.

\section{Study design, participants and ethics}

This was a prospective, controlled study with a 1-year follow-up of consecutive patients referred to our sleep clinic because of suspected OSA. Full inclusion and exclusion criteria are shown in supplementary table S1. In brief, participants were aged 18-60 years and free of any additional comorbid conditions. Study procedures were approved by the Ethics and Clinical Research Committee of the Aragón Institute of Health Sciences (protocol 10/231), and informed consent was obtained from each participant.

\section{Clinical data}

Demographic, anthropometric and clinical data were obtained during recruitment [23]. All participants had a physical examination of the upper airway by an ear, nose and throat specialist supplemented by nasopharyngolaryngoscopy and lateral cephalometric radiographs [24]. Daytime somnolence was assessed using the Epworth Sleepiness Scale (ESS) [25].

\section{Measurements}

Sleep study

In-home unattended sleep studies were performed at baseline and after a 1-year of follow-up. Recordings were scored manually following national guidelines [26] (see supplementary material for details).

\section{Pharyngeal lavage}

At baseline and after a 1-year follow-up, pharyngeal lavage (PHAL) samples were obtained (see supplementary material for details). Lavage fluid was centrifuged to obtain a cell pellet for flow cytometry. The cell-free supernatants were aliquoted and stored at $-80^{\circ} \mathrm{C}$ for further analyses of inflammatory cytokines.

\section{Flow cytometry}

Flow cytometry analysis was used to quantify the cell count and differential immediately after obtaining the lavage fluid and blood samples. Peripheral blood mononuclear cells and PHAL cells were stained to determine lymphocyte subpopulations.

\section{Inflammatory biomarkers}

Fasting blood and PHAL were collected on the morning after the sleep study, between 08:00 $\mathrm{h}$ and 10:00 h, at baseline and follow-up. Blood samples were immediately centrifuged for $20 \mathrm{~min}$ at $1800 \times \mathrm{g}$, and 
plasma samples were kept at $-80^{\circ} \mathrm{C}$ until assays were performed. The plasma concentration of CRP was determined by particle-enhanced immunonephelometry. Plasma and PHAL concentration of IL-6, IL-8 and TNF- $\alpha$ were determined by high-sensitivity ELISA (Invitrogen, Carlsbad, CA, USA).

\section{Treatment and follow-up}

The Spanish Respiratory Society guidelines for the management of OSA [26] were followed. In summary, nasal CPAP therapy was recommended for AHI $\geqslant 30$ events $\cdot h^{-1}$ or for an AHI between 5 and 30 with excessive daytime sleepiness $(E S S \geqslant 10)$ that interfered with daily activities. Upper airway surgery was offered as an alternative to all patients who could not tolerate or rejected therapy with CPAP and to participants who were not eligible for CPAP therapy according to the guidelines (supplementary table S2). Patients who did not receive treatment with CPAP or upper airway surgery were grouped as the "usual care" group. All participants were followed at the sleep clinic at 3, 6, 9 and 12 months after the initial visit.

\section{Statistical analyses}

Data are summarised as frequencies for categorical variables and median (interquartile range) for continuous variables. Baseline data for the groups studied were compared using Chi-squared, analysis of variance and Kruskal-Wallis tests, as appropriate. Continuous variables of inflammatory biomarkers in plasma and PHAL were normally distributed and log-transformed. Pearson's correlation coefficients were calculated adjusting for age, sex, body mass index (BMI), ESS and AHI. The difference between baseline and 1-year follow-up of biomarkers was assessed using the Wilcoxon signed-rank test or paired t-test, as appropriate. All analyses were repeated by separating the population into two groups according to BMI: $\leqslant 30 \mathrm{~kg} \cdot \mathrm{m}^{-2}$ versus $\geqslant 30 \mathrm{~kg} \cdot \mathrm{m}^{-2}$. Statistical analyses were performed with the STATA v.12.1 software (College Station, TX, USA).

\section{Results}

\section{Population characteristics}

A total of 143 participants were included in the study (figure 1). Of these, 26 had a normal sleep study and were non-snorers, 28 were snorers and had a normal sleep study and 89 had OSA (AHI $\geqslant 5$ events $\cdot \mathrm{h}^{-1}$ ). The baseline characteristics for all groups are presented in table 1 .

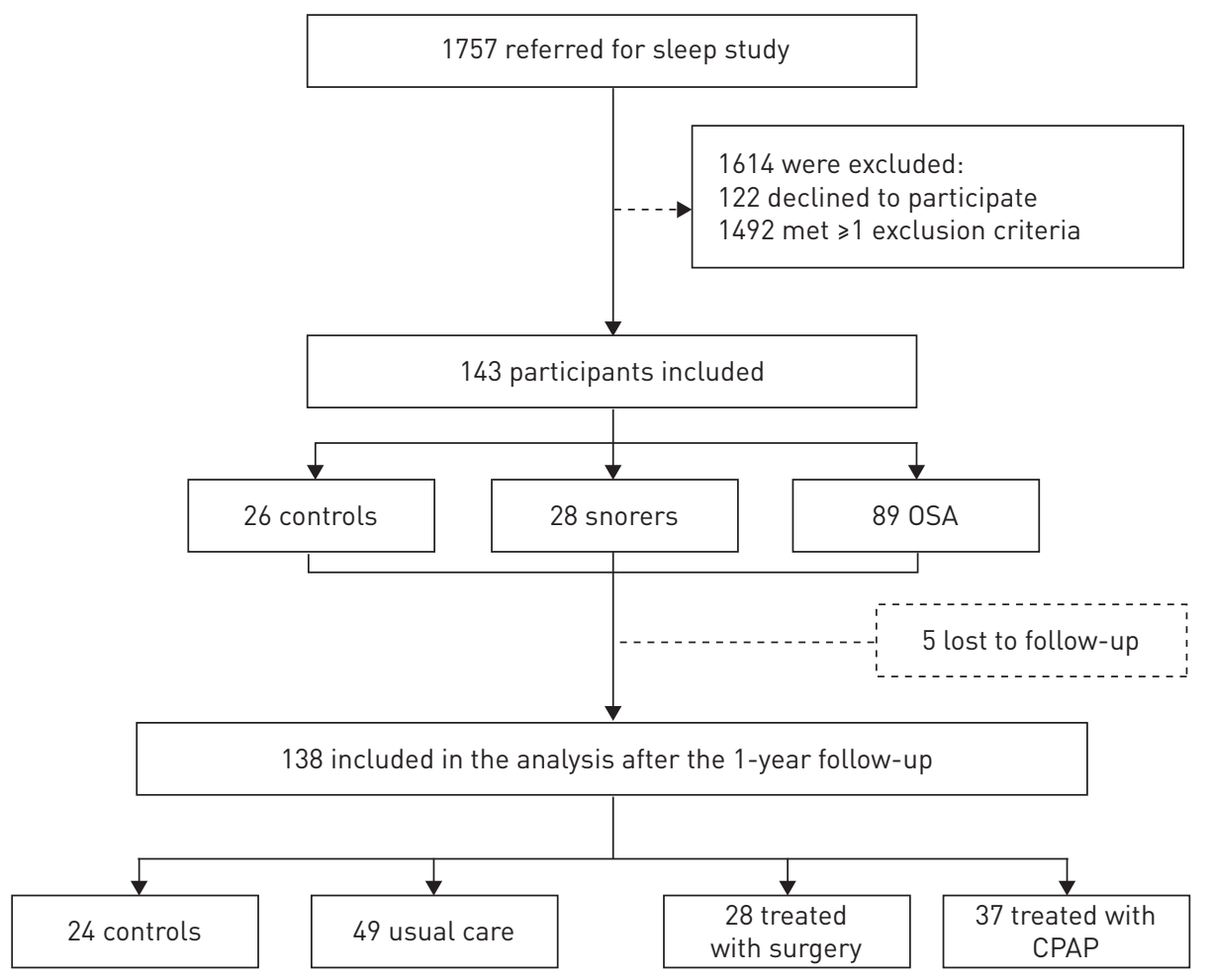

FIGURE 1 Study flow chart. Number of participants who were screened, assigned to a study group and included in the analyses after the 1-year follow-up according to treatment. OSA: obstructive sleep apnoea; CPAP: continuous positive airway pressure. 


\begin{tabular}{|c|c|c|c|c|}
\hline & Control & Snoring & OSA & p-value \\
\hline Participants & 26 & 28 & 89 & N/A \\
\hline Age years & 44 (38-53) & $42(33-46)$ & $44(36-56)$ & 0.561 \\
\hline Male sex n (\%) & $16(61)$ & $18(64)$ & $62(69)$ & 0.122 \\
\hline $\mathrm{BMI} \mathrm{kg} \cdot \mathrm{m}^{-2}$ & $27.9(25.2-31.1)$ & $28.9(26.9-32.1)$ & $29.1(27.1-33.9)$ & 0.014 \\
\hline ESS & $7(4-10)$ & $8(3-11)$ & $9(6-15)$ & 0.725 \\
\hline $\mathrm{AHI}$ events: $\mathrm{h}^{-1}$ & $2(0.5-3.2)$ & $2(1.0-3.5)$ & $28(12-44)$ & $<0.001$ \\
\hline СТ9० \% & 0 & $0(0-0.2)$ & $8.2(0-18.8)$ & $<0.001$ \\
\hline
\end{tabular}

Data are presented as median (interquartile range) unless otherwise stated. OSA: obstructive sleep apnoea; N/A: not applicable; BMI: body mass index; ESS: Epworth Sleepiness Scale (range 0-24); AHI: apnoea/ hypopnoea index; CT90: percentage of recording time when oxygen saturation of arterial blood $<90 \%$.

\section{PHAL and plasma analyses}

Table 2 provides an overview of the cytokines analysed and the cell population from plasma and PHAL in: 1) controls; 2) snorers; 3 ) mild-to-moderate OSA (AHI $\geqslant 5$ to $\leqslant 30$ events $\cdot h^{-1}$ ); and 4) severe OSA (AHI $\geqslant 30$ events $\cdot h^{-1}$ ).

For all samples, total cell counts in PHAL ranged from $1.3 \times 10^{6}$ per $\mathrm{mL}$ to $22.6 \times 10^{6}$ per $\mathrm{mL}$ with the majority of inflammatory cells being neutrophils (range: 96.9-99.7\%), the rest lymphocytes (range: $0.2-$ 3.0\%). Lymphocytes (in percentage leukocytes) were higher in severe OSA (median (interquartile range): $1.7(0.9-2.9))$, compared with the control $(0.7(0.3-1.4) ; \mathrm{p}<0.05)$ and snorer group $(1.0(07-2.1) ; \mathrm{p}<0.05)$. T-lymphocytes accounted for the majority of lymphocytes in all groups. $\mathrm{CD} 4^{+}$was the predominant $\mathrm{T}$-cell subclass and was significantly elevated in severe OSA (59\% (55-63\%)) compared with both control (54\% $(48-57 \%) ; \mathrm{p}<0.001)$ and snorer group (55\% (55-60\%); $\mathrm{p}<0.05)$ (figure 2). In PHAL, IL-6 was higher in patients with severe OSA $\left(3.6 \mathrm{pg} \cdot \mathrm{mL}^{-1}\left(2.2-6.1 \mathrm{pg} \cdot \mathrm{mL}^{-1}\right)\right)$ compared to the control $\left(2.4 \mathrm{pg} \cdot \mathrm{mL}^{-1}(1.2-\right.$ $\left.\left.4.3 \mathrm{pg} \cdot \mathrm{mL}^{-1}\right) ; \mathrm{p}<0.01\right)$ and snorer group $\left(2.7 \mathrm{pg} \cdot \mathrm{mL}^{-1}\left(1.3-4.7 \mathrm{pg} \cdot \mathrm{mL}^{-1}\right) ; \mathrm{p}<0.05\right)$. IL-8 was also higher in severe OSA $\left(5.1 \mathrm{pg} \cdot \mathrm{mL}^{-1}\left(3.6-7.6 \mathrm{pg} \cdot \mathrm{mL}^{-1}\right)\right)$ than in the control $\left(2.5 \mathrm{pg} \cdot \mathrm{mL}^{-1}\left(1.7-4.3 \mathrm{pg} \cdot \mathrm{mL}^{-1}\right) ; \mathrm{p}<0.01\right)$ and snorer group $\left(2.9 \mathrm{pg} \cdot \mathrm{mL}^{-1}\left(1.9-4.9 \mathrm{pg} \cdot \mathrm{mL}^{-1}\right) ; \mathrm{p}<0.05\right)$. IL-8 was also significantly higher in moderate OSA compared to the control group $\left(4.2 \mathrm{mg} \cdot \mathrm{mL}^{-1} \quad\left(2.7-5.2 \mathrm{pg} \cdot \mathrm{mL}^{-1}\right)\right.$ versus $2.5 \mathrm{pg} \cdot \mathrm{mL}^{-1} \quad(1.7-$ $4.3 \mathrm{pg} \cdot \mathrm{mL}^{-1}$ ); $\mathrm{p}<0.5$ ) (figure 2). In linear regression analysis, CD4 $4^{+}$, IL-6 and IL-8 had a positive correlation with AHI $(\mathrm{r}=0.29, \mathrm{p}<0.01 ; \mathrm{r}=0.18, \mathrm{p}=0.04$; and $\mathrm{r}=0.41, \mathrm{p}<0.01$, respectively).

The percentage of circulating lymphocyte subpopulation did not differ across groups. There was a trend for increased inflammatory cytokines in plasma by OSA severity, but no significant differences were found between groups (table 2). There was no significant correlation between plasma inflammatory cytokines and AHI or percentage of recording time with an arterial oxygen saturation $<90 \%$ (CT90) as a surrogate of OSA severity.

\section{Relationship between pharyngeal and systemic inflammation}

Pearson's correlation coefficients adjusted for age, sex, BMI, ESS and AHI between inflammatory biomarkers measured in PHAL and plasma are presented in table 3. None of the biomarkers studied showed a significant relationship, either for the whole cohort or when the analyses were performed separately for the participants with or without obesity defined as BMI $\geqslant 30 \mathrm{~kg} \cdot \mathrm{m}^{-2}$ and $<30 \mathrm{~kg} \cdot \mathrm{m}^{-2}$, respectively.

\section{Follow-up}

The 1-year follow-up was completed by 138 participants (96.5\%). Five patients were excluded from the analysis: two had OSA surgery at 3 and 6 months after initiating CPAP therapy; one had uvulopalatopharyngoplasty at baseline and initiated CPAP 4 months later; and two patients in the control group declined re-examination. Patient characteristics according to treatment received are shown in supplementary table S3. The mean time of CPAP use was $5.8 \mathrm{~h}$ per night (range 3.2-9.3 h per night). Individual changes in AHI are shown in supplementary figure S1.

In controls and OSA patients who did not receive treatment with CPAP or upper airway surgery (the "usual care" group), there were no changes in the PHAL biomarkers (table 4). Patients who had CPAP therapy or surgery showed a reduction in the PHAL inflammatory cell population. This reduction was significant for total leukocytes $(\mathrm{p}=0.034)$, percentage lymphocytes $(\mathrm{p}=0.008)$ and percentage $\mathrm{CD} 4^{+} \mathrm{T}$-cells $(\mathrm{p}=0.02)$ in the CPAP treatment group, and for percentage lymphocytes $(\mathrm{p}=0.03)$ and percentage $\mathrm{CD} 4^{+}$ T-cells $(p=0.04)$ in the surgery group. In PHAL samples, IL-6 was significantly reduced only in patients 
TABLE 2 Baseline pharyngeal lavage and plasma inflammatory biomarkers

\begin{tabular}{|c|c|c|c|c|}
\hline & Control & Snoring & Mild-to-moderate OSA & Severe OSA \\
\hline Participants & 26 & 28 & 42 & 47 \\
\hline \multicolumn{5}{|l|}{ Lavage } \\
\hline Lymphocytes \% leukocytes & $0.7(0.3-1.4)$ & $1.0(0.7-2.1)$ & $1.4(0.8-2.5)$ & $1.7(0.9-2.9)^{\#, \pi}$ \\
\hline T-cells \% lymphocytes & 92 (89-96) & 92 (90-95) & $94(91-96)$ & $96(93-97)^{\#}$ \\
\hline $\mathrm{CD}^{+} \% \mathrm{~T}$-cells & $54(48-57)$ & $55(49-60)$ & $58(54-61)$ & $59(55-63)^{9,+}$ \\
\hline NK cells \% lymphocytes & $4(2-6)$ & $3(1-4)$ & $4(2-5)$ & $3(1-5)$ \\
\hline $\mathrm{IL}-6 \mathrm{pg} \cdot \mathrm{mL}^{-1}$ & $2.4(1.2-4.3)$ & $2.7(1.3-4.7)$ & $3.2(1.6-4.9)$ & $3.6(2.2-6.1)^{9,++}$ \\
\hline $\mathrm{IL}-8 \mathrm{pg} \cdot \mathrm{mL}^{-1}$ & $2.5(1.7-4.3)$ & $2.9(1.9-4.9)$ & $4.2(2.7-5.2)^{\#}$ & $5.1(3.6-7.6)^{9,+}$ \\
\hline $\mathrm{TNF}-\alpha \mathrm{pg} \cdot \mathrm{mL}^{-1}$ & $1.2(0.8-2.1)$ & $1.5(0.9-2.7)$ & $1.8(1.1-3.2)$ & $2.1(1.7-4.2)$ \\
\hline \multicolumn{5}{|l|}{ Plasma } \\
\hline Lymphocytes \% leukocytes & $29.8 \pm 9.7$ & $29.1 \pm 8.2$ & $29.6 \pm 6.8$ & $30.9 \pm 7.3$ \\
\hline NK cells $\%$ lymphocytes & $11.8 \pm 5.6$ & $13.9 \pm 5.9$ & $10.6 \pm 4.6$ & $12.4 \pm 6.1$ \\
\hline $\mathrm{CRP} \mathrm{mg} \cdot \mathrm{dL}^{-1}$ & $0.15(0.10-0.28)$ & $0.12(0.08-0.35)$ & $0.17(0.10-0.43)$ & $0.19(0.11-0.44)$ \\
\hline $\mathrm{IL}-6 \mathrm{pg} \cdot \mathrm{mL}^{-1}$ & $7.12(6.61-7.90)$ & $6.91(6.55-7.15)$ & $7.24(6.65-8.26)$ & $7.44(6.77-8.89)$ \\
\hline $\mathrm{IL}-8 \mathrm{pg} \cdot \mathrm{mL}^{-1}$ & $21.3(19.2-22.4)$ & $22.1(19.7-24.5)$ & $21.6(20.4-22.9)$ & $22.3(20.8-23.1)$ \\
\hline $\mathrm{TNF}-\alpha \mathrm{pg} \cdot \mathrm{mL}^{-1}$ & 4.35 (4.01-4.99) & $4.45(4.03-5.12)$ & $4.54(4.09-5.25)$ & $4.46(4.21-5.06)$ \\
\hline
\end{tabular}

Data are presented as median (interquartile range) or as mean \pm SD, unless otherwise stated. OSA: obstructive sleep apnoea; NK: natural killer; IL: interleukin; TNF- $\alpha$ : tumour necrosis factor- $\alpha$; CRP: C-reactive protein. ${ }^{\#}$ : $p<0.05$ compared with the control group; ${ }^{\text {ๆ }}$ : $<<0.05$ compared with the snoring group; ${ }^{+}: p<0.001$ compared with the control group.

treated with CPAP $(\mathrm{p}=0.008)$, whereas IL- 8 was decreased in patients treated either with CPAP $(\mathrm{p}=0.006)$ or surgery $(\mathrm{p}=0.021)$. In secondary analyses grouping patients according to the type of surgery performed (nasal, pharyngeal or both) or mean hours of CPAP used (e.g. more or less than $4 \mathrm{~h}$ per night), the same changes in the biomarkers analysed were found after 1 year of follow-up, i.e. a reduction in local inflammatory biomarkers in PHAL but not in plasma.

\section{Discussion}

This is the first study aimed at investigating the relationship between local (upper airway) and peripheral (systemic) inflammation in patients with OSA. The study did not find a relationship between local inflammatory cytokines and inflammatory cells collected in the upper airway using PHAL and plasma from peripheral blood. Inflammatory biomarkers commonly used in OSA research were evaluated. However, to definitively reject the spill-over hypothesis, this work would have to be performed using a specific biomarker unique to the upper airway, or somehow specifically identified/tagged as originating in the upper airway. These biomarkers could then be measured systemically.

The relationship between local (target organ) and systemic inflammation has been demonstrated previously in other respiratory conditions, such as chronic obstructive pulmonary disease [27]. Such findings prompted the "spill-over" hypothesis, which suggested the overflow of inflammatory cytokines reaching the blood stream from a local source [28]. Systemic inflammation may also contribute to weakening the respiratory muscles [29] and destabilising loop gain and respiratory control, thus impairing the protective airway patency mechanisms [30].

This work is critically essential given that the investigation of inflammation present in OSA patients at the source of airway collapse (upper airway) and its relationship to a systemic effect was performed using a novel technique. The PHAL technique is noninvasive and evaluates the local effects of intermittent collapse and/or snoring during repetitive cycles in OSA patients. In PHAL, an increase in inflammatory cells in patients with OSA was found, but this was not present in simple snorers or controls. These changes were mainly caused by activated T-cells and corroborate previous findings of lymphocytosis in PHAL by Hauber et al. [31], and in uvula tissue by Boyd et al. [4] in patients with OSA. However, there is no evidence that the levels of inflammatory cells in PHAL are true surrogates of the inflammatory 

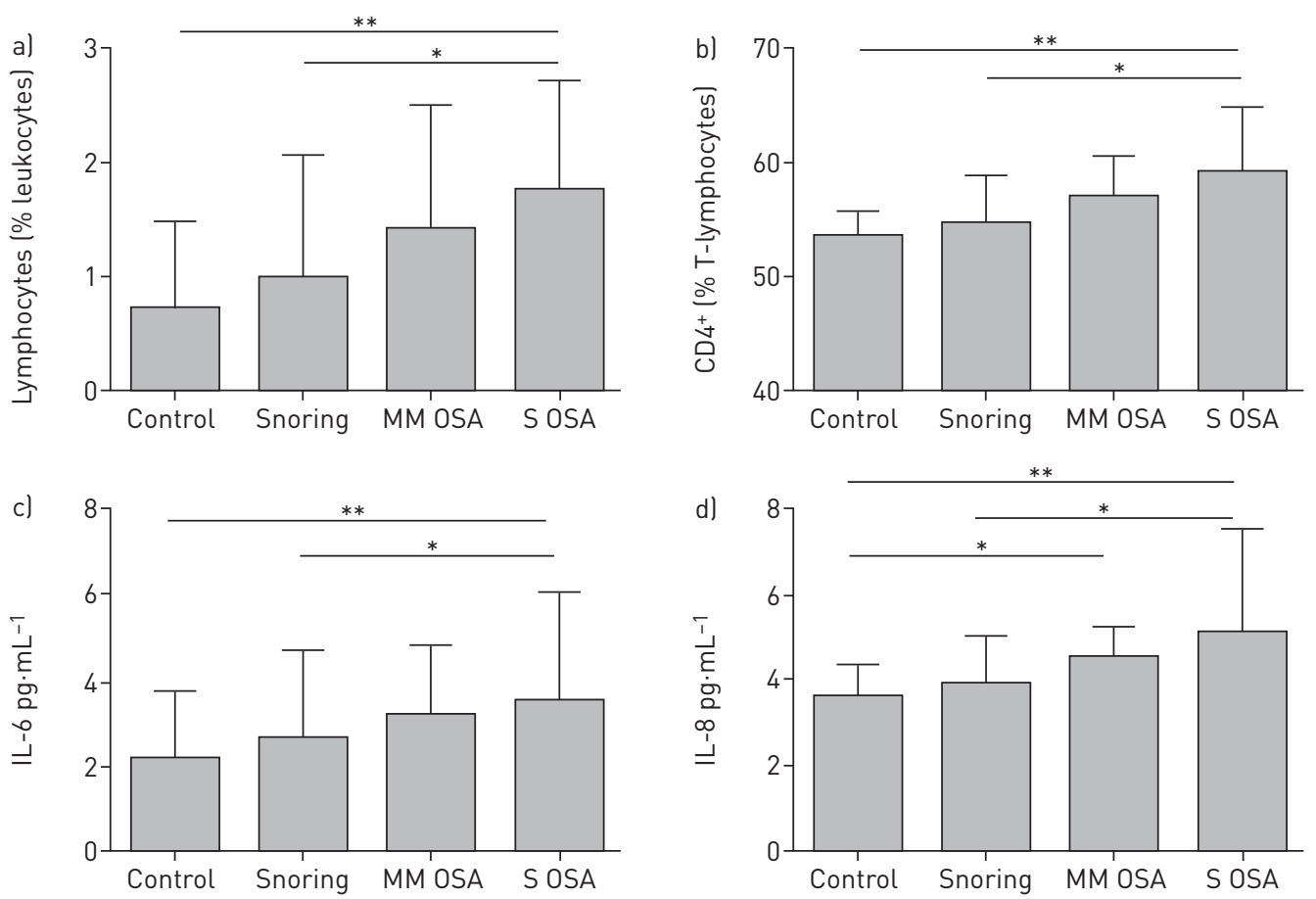

FIGURE 2 a) Pharyngeal lavage lymphocytes (as percentage of total leukocytes), b) CD4+ (as percentage of T-lymphocytes), c) interleukin (IL)-6 and d) IL-8 in controls, snoring patients, and in patients with mild-to-moderate (MM OSA) and severe obstructive sleep apnoea (S OSA). Data are presented as median and interquartile ranges. ${ }^{*}: p<0.05 ;{ }^{* *}: p<0.01$.

infiltration of tissues of the upper airway because there are no studies to date assessing both PHAL and tissue sampling in the same individuals.

For the first time, an increase of proinflammatory cytokines in PHAL was found, including IL-6 and IL-8, in patients with OSA compared to healthy controls. This is in agreement with KimOFF et al. [32] who found increased expression of IL- 6 and IL- $1 \alpha$ within the mucosa of the upper airway tissue of patients with severe OSA. These authors also found increased expression of RANTES (regulated on activation, normal T-cell expressed and secreted) and increased connective tissue within the muscle fascicles.

TABLE 3 Adjusted correlation matrix of the association between pharyngeal and plasma biomarkers of inflammation

Pharyngeal lavage

IL-6 IL-8 TNF- $\alpha$ Leukocytes Lymphocytes T-cells CD4 $^{+} \quad \mathrm{CD8}^{+}$B-cells NK cells

\begin{tabular}{|c|c|c|c|c|c|c|c|c|c|c|}
\hline \multicolumn{11}{|l|}{ Plasma } \\
\hline CRP & 0.123 & 0.032 & 0.034 & 0.089 & 0.012 & 0.043 & 0.034 & 0.067 & 0.006 & 0.010 \\
\hline IL-6 & & 0.108 & 0.056 & 0.015 & -0.082 & -0.011 & -0.042 & -0.043 & -0.006 & 0.013 \\
\hline IL-8 & & 0.101 & 0.056 & 0.012 & -0.067 & -0.022 & -0.025 & 0.046 & 0.012 & 0.020 \\
\hline TNF- $\alpha$ & & & 0.005 & 0.003 & 0.044 & 0.023 & 0.078 & -0.032 & 0.005 & 0.033 \\
\hline Leukocytes & & & & -0.007 & 0.032 & 0.007 & 0.005 & -0.023 & 0.004 & 0.031 \\
\hline Lymphocytes & & & & & 0.122 & 0.061 & 0.075 & 0.102 & -0.002 & 0.006 \\
\hline T-cells & & & & & & 0.065 & 0.066 & 0.084 & -0.054 & -0.077 \\
\hline $\mathrm{CD}^{+}$ & & & & & & & 0.101 & 0.088 & 0.001 & 0.007 \\
\hline $\mathrm{CD} 8^{+}$ & & & & & & & & 0.039 & -0.077 & -0.075 \\
\hline B-cells & & & & & & & & & 0.018 & -0.006 \\
\hline NK cells & & & & & & & & & & 0.106 \\
\hline
\end{tabular}

Data represent the correlation coefficient adjusted for age, sex, body mass index, Epworth Sleepiness Scale and apnoea/hypopnoea index. CRP: C-reactive protein; IL: interleukin; TNF- $\alpha$ : tumour necrosis factor- $\alpha$; NK: natural killer. 
TABLE 4 Baseline, 12-month and treatment effect for all inflammatory biomarkers

\begin{tabular}{|c|c|c|c|c|c|c|c|c|}
\hline & \multicolumn{2}{|c|}{ Control $^{\#}$} & \multicolumn{2}{|c|}{ Usual care ${ }^{\pi}$} & \multicolumn{2}{|c|}{ Surgery $^{+}$} & \multicolumn{2}{|c|}{ CPAP§ } \\
\hline & Baseline & 1 year & Baseline & 1 year & Baseline & 1 year & Baseline & 1 year \\
\hline \multicolumn{9}{|l|}{ Lavage } \\
\hline Leukocytes $\times 10^{4}$ cells $\cdot \mathrm{mL}^{-1}$ & $12.0(8.0-24.2)$ & $11.1(8.3-22.1)$ & $13.3(8.1-24.5)$ & $12.4(8.2-23.7)$ & $14.1(8.9-27.4)$ & $12.1(8.2-21.3)$ & $15.9(9.9-32.1)$ & $12.4(8.1-27.2)^{*}$ \\
\hline Lymphocytes \% leukocytes & $0.6(0-1.3)$ & $0.6(0-1.20)$ & $1.1(0.8-2.7)$ & $1.2(0.9-3.0)$ & $1.5(0.8-3.1)$ & $1.1(0.7-2.3)^{*}$ & $1.9(1.0-3.9)$ & $1.1(0.8-3.0)^{* *}$ \\
\hline T-cells \% lymphocytes & $91(88-96)$ & $92(89-96)$ & $93(91-95)$ & $94(90-95)$ & $94(92-97)$ & $92(91-95)^{*}$ & $96(93-98)$ & $92(90-95)^{* *}$ \\
\hline $\mathrm{CD4}^{+} \% \mathrm{~T}$-cells & $54(47-56)$ & $53(46-56)$ & $55(50-62)$ & $56(49-60)$ & $59(55-64)$ & $54(50-61)$ & $60(55-67)$ & $56(51-62)^{*}$ \\
\hline CD8 $\%$ T-cells & $31(24-35)$ & $32(25-37)$ & $33(27-38)$ & $34(29-39)$ & $31(25-36)$ & $34(30-38)$ & $30(22-39)$ & $33(25-38)$ \\
\hline B-cells \% lymphocytes & $3(1-4)$ & $3(1-4)$ & $2(0-4)$ & $2(1-4)$ & $2(1-3)$ & $3(1-4)$ & $2(0-4)$ & $3(1-5)$ \\
\hline NK cells $\%$ lymphocytes & $4(2-6)$ & $3(1-5)$ & $3(1-5)$ & $4(2-6)$ & $2(2-5)$ & $3(1-5)$ & $2(0-5)$ & $3(1-5)$ \\
\hline $\mathrm{IL}-6 \mathrm{pg} \cdot \mathrm{mL}^{-1}$ & $2.4(1.2-4.3)$ & $2.1(1.1-4.1)$ & $2.2(1.3-4.7)$ & $2.4(1.1-4.3)$ & $3.1(1.3-4.2)$ & $2.6(0.7-3.2)$ & $3.9(2.8-6.9)$ & $2.4(1.4-3.9)^{*}$ \\
\hline $\mathrm{IL}-8 \mathrm{pg} \cdot \mathrm{mL}^{-1}$ & $2.5(1.7-4.3)$ & $2.6(1.9-3.9)$ & $2.3(1.4-4.2)$ & $2.5(1.1-4.9)$ & $3.9(1.9-4.1)$ & $2.6(1.2-3.7)^{*}$ & $5.9(2.8-7.9)$ & $3.9(2.0-5.2)^{* *}$ \\
\hline $\mathrm{TNF}-\alpha \mathrm{pg} \cdot \mathrm{mL}^{-1}$ & $1.4(0.9-2.3)$ & $1.6(0.9-2.3)$ & $1.4(0.8-2.5)$ & $1.5(0.9-2.6)$ & $1.9(1.3-3.7)$ & $1.7(1.0-2.6)$ & $2.8(1.9-4.8)$ & $2.2(1.5-3.9)$ \\
\hline \multicolumn{9}{|l|}{ Plasma } \\
\hline Lymphocytes \% leukocytes & $29.4 \pm 9.4$ & $29.9 \pm 9.9$ & $29.8 \pm 8.9$ & $30.2 \pm 9.1$ & $29.1 \pm 8.1$ & $28.3 \pm 8.8$ & $30.1 \pm 8.3$ & $29.1 \pm 7.8$ \\
\hline T-cells \% lymphocytes & $78.7 \pm 18.1$ & $77.3 \pm 19.2$ & $75.7 \pm 21.5$ & $76.2 \pm 20.6$ & $77.8 \pm 19.9$ & $75.6 \pm 18.7$ & $77.4 \pm 22.9$ & $75.8 \pm 18.9$ \\
\hline $\mathrm{CD}^{+} \%$ T-cells & $60.7 \pm 22.4$ & $61.5 \pm 21.9$ & $61.1 \pm 21.4$ & $61.9 \pm 22.1$ & $61.9 \pm 21.3$ & $61.8 \pm 22.0$ & $62.9 \pm 18.9$ & $60.8 \pm 20.8$ \\
\hline CD8 $\%$ T-cells & $34.4 \pm 13.2$ & $34.5 \pm 12.9$ & $34.1 \pm 16.3$ & $33.9 \pm 18.7$ & $32.1 \pm 14.4$ & $33.0 \pm 15.2$ & $32.8 \pm 15.2$ & $33.3 \pm 13.2$ \\
\hline B-cells \% lymphocytes & $8.7 \pm 3.2$ & $8.8 \pm 2.9$ & $10.2 \pm 5.1$ & $9.8 \pm 3.8$ & $12.1 \pm 3.5$ & $11.3 \pm 4.1$ & $12.9 \pm 5.2$ & $13.8 \pm 6.7$ \\
\hline $\mathrm{CRP} \mathrm{mg} \cdot \mathrm{dL}^{-1}$ & $0.17(0.12-0.28)$ & $0.18(0.11-0.25)$ & $0.15(0.09-0.31)$ & $0.13(0.07-0.25)$ & $0.23(0.11-0.53)$ & $0.18(0.12-0.35)$ & $0.20(0.11-0.54)$ & $0.21(0.12-0.24)$ \\
\hline $\mathrm{IL}-6 \mathrm{pg} \cdot \mathrm{mL}^{-1}$ & $7.02(6.72-7.46)$ & $6.67(5.23-6.76)$ & $6.33(6.79-8.05)$ & $6.18(5.38-8.48)$ & $7.35(6.99-8.34)$ & $6.79(5.07-6.54)$ & $6.87(6.74-7.25)$ & $5.92(5.13-6.11)$ \\
\hline $\mathrm{IL}-8 \mathrm{pg} \cdot \mathrm{mL}^{-1}$ & $21.1(19.7-21.9)$ & $23.4(22.8-24.0)$ & $21.9(20.8-23.1)$ & $23.1(20.9-24.3)$ & $21.6(19.4-23.3)$ & $18.9(18.1-23.4)$ & $22.9(21.9-24.1)$ & $24.5(23.0-25.1)$ \\
\hline $\mathrm{TNF}-\alpha \mathrm{pg} \cdot \mathrm{mL}^{-1}$ & $4.36(4.01-4.82)$ & $4.36(3.95-4.76)$ & $4.38(4.02-5.20)$ & $4.50(4.17-4.67)$ & $4.64(4.05-5.09)$ & $4.32(4.28-4.49)$ & $4.91(4.26-5.32)$ & $4.37(4.19-4.62)$ \\
\hline
\end{tabular}


The final result of these histological changes is a more collapsible and dysfunctional upper airway in OSA. Although tissue samples were not available for the cohort in this study, the reduction of both inflammatory cytokines and inflammatory cells found in PHAL after treatment suggests that CPAP or upper airway surgery in OSA may impact tissue inflammatory response and perhaps reverse the histological changes of the upper airway that can be observed in OSA. These changes may partly explain the increase in the cross-sectional area of the pharynx after treatment with CPAP [32] and/or upper airway surgery $[33,34]$. This study cannot explain why PHAL inflammation decreases with surgery or CPAP, especially taking into account the different baseline AHI of both groups. It is possible that snoring, which was eliminated with both techniques, can play a role in improving the inflammatory status of the pharyngeal mucosa. Further studies with snorers without OSA might clarify this issue.

Upper airway surgery or CPAP treatment had no effect on inflammatory biomarkers in plasma after a 12-month follow-up. КАТАОКA et al. [35] studied the effect of upper airway surgery on circulating inflammatory biomarkers in OSA. They found a reduction in plasma levels of TNF- $\alpha$ after 1 week of surgical treatment. However, their sample was small and there were no data on concomitant comorbidities. In our study, the cohort included patients stratified by OSA severity without any concomitant comorbidity, including morbid obesity. Similarly, changes in peripheral inflammatory cytokines after 1 year of adequate treatment with CPAP were not found (supplementary figure S1).

Today, the debate continues about the association of OSA with persistent systemic inflammation. In fact, baseline values of the most common biomarkers used to study the effect of CPAP on plasma inflammation vary widely (supplementary table S4). These differences could be explained by the selection of patients (e.g. differences in sex, age and BMI), techniques used to identify the biomarkers and the timing of blood sampling. This study was not designed to evaluate the effect of CPAP on circulatory biomarkers; however, baseline inflammatory circulating biomarkers were found to be comparable with recent randomised controlled trials and in agreement with these results [36, 37]. KoHLER et al. [37] showed no improvement in inflammatory biomarkers in the blood of patients with OSA after 1 month of CPAP treatment and Chirinos et al. [38] found no effect of CPAP treatment on CRP levels over 24 weeks in patients with moderate-to-severe OSA. Nevertheless, the lack of changes in systemic inflammation were accompanied by improvement in endothelial function and a fall in systolic blood pressure [38, 39]. Finally, in the Multicentre Obstructive Sleep Apnoea Interventional Cardiovascular (MOSAIC) study, a trial designed to compare CPAP therapy with no CPAP in minimally symptomatic OSA, STRADLING et al. [40] did not find changes in IL-6, IL-10, CRP and TNF- $\alpha$.

This study has limitations. First, this was not a randomised trial and the results should be considered as hypothesis-generating only. However, relatively well-matched groups of patients were studied and provided data on the1-year follow-up of OSA treatment effects. Sleep studies were also performed in all patients, so that the effect of treatment could be evaluated and related to the change in the AHI. Also, given the inherent heterogeneous nature of these patients and their substantial clinical variability on presentation, this sample may not be perfectly representative of the general population. Finally, besides studying many inflammatory cytokines, this study did not assess other biomarkers that have been found to be elevated in OSA [41] and could be implicated in local and systemic inflammatory responses or some potential mechanisms, such as oxidative stress or endothelial dysfunction. Therefore, further studies seem warranted.

\section{Conclusions}

This study demonstrated a reduction in certain biomarkers of inflammation found in PHAL after long-term treatment with CPAP and/or upper airway surgery in patients with moderate-to-severe OSA. Further proof of this association warrants data from randomised studies. Regulators of pharyngeal inflammation (proinflammatory and anti-inflammatory) also deserve further study that can be pursued with this proposed model. Finally, this work sets the stage for novel mechanistic studies using a minimally invasive technique, PHAL. Results from such studies could potentially be targeted by new drug development or other treatment modalities.

\section{Acknowledgements}

We would like to thank all the staff in the Otorhinolaryngology and Pulmonary Departments in the Hospital Universitario Miguel Servet and all the patients who participated in the study. We would like to thank Andrew L. Ries, UCSD, San Diego, USA, for revising the article.

Contributors: J.M. Marin had the original idea for the study; E. Vicente, S.J. Carrizo, M. Forner, M. Marin-Oto, P. Vicente, R. González and A.V. Gil collected the clinical data; and C.S. Osuna performed the flow cytometry analysis. E. Vicente, C.S. Osuna, X. Soler and J.M. Marin developed the plan of analysis, and J.M. Marin, E. Vicente and $\mathrm{X}$. Soler drafted the article. All the authors critically reviewed and contributed to the final version of this article.

A section of this material was presented as an oral presentation during the 2015 European Respiratory Society International Congress. 


\section{References}

1 Paulsen FP, Steven P, Tsokos M, et al. Upper airway epithelial structural changes in obstructive sleep-disordered breathing. Am J Respir Crit Care Med 2002; 166: 501-509.

2 Zakkar M, Sekosan M, Wenig B, et al. Decrease in immunoreactive neutral endopeptidase in uvula epithelium of patients with obstructive sleep apnea. Ann Otol Rhinol Laryngol 1997; 106: 474-477.

3 Llorente Arenas EM, Vicente González EA, Marín JM, et al. Cambios histologicos en el paladar blando en pacientes con apnea obstructiva del sueno. [Histologic changes in soft palate in patients with obstructive sleep apnea.] An Otorrinolaringol Ibero Am 2001; 28: 467-476.

4 Boyd JH, Petrof BJ, Hamid Q, et al. Upper airway muscle inflammation and denervation changes in obstructive sleep apnea. Am J Respir Crit Care Med 2004; 170: 541-546.

5 Puig F, Rico F, Almendros I, et al. Vibration enhances interleukin-8 release in a cell model of snoring induced airway inflammation. Sleep 2005; 28: 1312-1316.

6 Chua AP, Aboussouan LS, Minai OA, et al. Long-term continuous positive airway pressure therapy normalizes high exhaled nitric oxide levels in obstructive sleep apnea. J Clin Sleep Med 2013; 9: 529-535.

7 Carpagnano GE, Kharitonov SA, Resta O, et al. 8-Isoprostane, a marker of oxidative stress, is increased in exhaled breath condensate of patients with obstructive sleep apnea after night and is reduced by continuous positive airway pressure therapy. Chest 2003; 124: 1386-1392.

8 Goldbart AD, Krishna J, Li RC, et al. Inflammatory mediators in exhaled breath condensate of children with obstructive sleep apnea syndrome. Chest 2006; 130: 143-148.

9 Li AM, Hung E, Tsang T, et al. Induced sputum inflammatory measures correlate with disease severity in children with obstructive sleep apnoea. Thorax 2007; 62: 75-79.

10 Devouassoux G, Lévy P, Rossini E, et al. Sleep apnea is associated with bronchial inflammation and continuous positive airway pressure-induced airway hyperresponsiveness. J Allergy Clin Immunol 2007; 119: 597-603.

11 Ross R. Atherosclerosis: an inflammatory disease. N Engl J Med 1999; 340: 115-126.

12 Hansson GK, Hermansson A. The immune system in atherosclerosis. Nat Immunol 2011; 12: 204-212.

13 Pack AI, Gislason T. Obstructive sleep apnea and cardiovascular disease: a perspective and future directions. Prog Cardiovasc Dis 2009; 51: 434-451.

14 Shamsuzzaman ASM, Winnicki M, Lanfranchi P, et al. Elevated C-reactive protein in patients with obstructive sleep apnea. Circulation 2002; 105: 2462-2464.

15 Yokoe T, Minoguchi K, Matsuo H, et al. Elevated levels of C-reactive protein and interleukin-6 in patients with obstructive sleep apnea syndrome are decreased by nasal continuous positive airway pressure. Circulation 2003; 107: 1129-1134.

16 Bastard JP, Maachi M, Lagathu C, et al. Recent advances in the relationship between obesity, inflammation, and insulin resistance. Eur Cytokine Netw 2006; 17: 4-12.

17 Taheri S, Austin D, Lin L, et al. Correlates of serum C-reactive protein (CRP): no association with sleep duration or sleep disordered breathing. Sleep 2007; 30: 991-996.

18 Arnardottir ES, Maislin G, Schwab RJ, et al. The interaction of obstructive sleep apnea and obesity on the inflammatory markers C-reactive protein and interleukin-6: the Icelandic Sleep Apnea Cohort. Sleep 2012; 35: 921-932.

19 Ryan S, McNicholas WT. Intermittent hypoxia and activation of inflammatory molecular pathways in OSAS. Arch Physiol Biochem 2008; 114: 261-266.

20 Greenberg $\mathrm{H}$, Ye X, Wilson $\mathrm{D}$, et al. Chronic intermittent hypoxia activates nuclear factor-kappaB in cardiovascular tissues in vivo. Biochem Biophys Res Commun 2006; 343: 591-596.

21 Jelic S, Le Jemtel TH. Inflammation, oxidative stress, and the vascular endothelium in obstructive sleep apnea. Trends Cardiovasc Med 2008; 18: 253-260.

22 Gottlieb DJ, Punjabi NM, Mehra R, et al. CPAP versus oxygen in obstructive sleep apnea. N Engl J Med 2014; 370: 2276-2285.

23 Marin JM, Agusti A, Villar I, et al. Association between treated and untreated obstructive sleep apnea and risk of hypertension. JAMA 2012; 307: 2169-2176.

24 Vicente E, Marín JM, Carrizo S, et al. Tongue-base suspension in conjunction with uvulopalatopharyngoplasty for treatment of severe obstructive sleep apnea: long-term follow-up results. Laryngoscope 2006; 116: 1223-1227.

25 Johns MW. A new method for measuring daytime sleepiness: the Epworth sleepiness scale. Sleep 1991; 14: 540-545.

26 Montserrat JM, Amilibia J, Barbé F, et al. Tratamiento del síndrome de las apneas-hipoapneas durante el sueño. [Treatment of sleep apnea-hypoapnea syndrome.] Arch Bronconeumol 1998; 34: 204-206.

27 Sinden NJ, Stockley RA. Systemic inflammation and comorbidity in COPD: a result of 'overspill' of inflammatory mediators from the lungs? Review of the evidence. Thorax 2010; 65: 930-936.

28 Teichert T, Vossoughi M, Vierkötter A, et al. Investigating the spill-over hypothesis: analysis of the association between local inflammatory markers in sputum and systemic inflammatory mediators in plasma. Environ Res 2014; 134: 24-32.

29 Reid MB, Lännergren J, Westerblad H. Respiratory and limb muscle weakness induced by tumor necrosis factor-alpha: involvement of muscle myofilaments. Am J Respir Crit Care Med 2002; 166: 479-484.

30 Huxtable AG, Vinit S, Windelborn JA, et al. Systemic inflammation impairs respiratory chemoreflexes and plasticity. Respir Physiol Neurobiol 2011; 178: 482-489.

31 Hauber H-P, Rüller S, Müller E, et al. Pharyngeal lavage lymphocytosis in patients with obstructive sleep apnea: a preliminary observation. PLoS One 2011; 6: e16277.

32 Kimoff RJ, Hamid Q, Divangahi M, et al. Increased upper airway cytokines and oxidative stress in severe obstructive sleep apnoea. Eur Respir J 2011; 38: 89-97.

33 Ryan CF, Lowe AA, Li D, et al. Magnetic resonance imaging of the upper airway in obstructive sleep apnea before and after chronic nasal continuous positive airway pressure therapy. Am Rev Respir Dis 1991; 144: 939-944.

34 Li HY, Li KK, Chen NH, et al. Three-dimensional computed tomography and polysomnography findings after extended uvulopalatal flap surgery for obstructive sleep apnea. Am J Otolaryngol 2005; 26: 7-11.

35 Kataoka T, Enomoto F, Kim R, et al. The effect of surgical treatment of obstructive sleep apnea syndrome on the plasma TNF-alpha levels. Tohoku J Exp Med 2004; 204: 267-272. 
36 Kohler M, Stoewhas AC, Ayers L, et al. Effects of continuous positive airway pressure therapy withdrawal in patients with obstructive sleep apnea: a randomised controlled trial. Am J Respir Crit Care Med 2011; 184: 1192-1199.

37 Kohler M, Ayers L, Pepperell JC, et al. Effects of continuous positive airway pressure on systemic inflammation in patients with moderate to severe obstructive sleep apnoea: a randomised controlled trial. Thorax 2009; 64: 67-73.

38 Chirinos JA, Gurubhagavatula I, Teff K, et al. CPAP, weight loss, or both for obstructive sleep apnea. $N$ Engl J Med 2014; 370: 2265-2275.

39 Kohler M, Craig S, Pepperell JC, et al. CPAP improves endothelial function in patients with minimally symptomatic OSA: results from a subset study of the MOSAIC trial. Chest 2013; 144: 896-902.

40 Stradling JR, Craig SE, Kohler M, et al. Markers of inflammation: data from the MOSAIC randomised trial of CPAP for minimally symptomatic OSA. Thorax 2015; 70: 181-182.

41 Jelic S, Padeletti M, Kawut SM, et al. Inflammation, oxidative stress, and repair capacity of the vascular endothelium in obstructive sleep apnea. Circulation 2008; 117: 2270-2278. 